Ипатова A.B. О тенденциях развития институтов реализации промышленной политики в Ростовской области

УДК 3.33.338.2

DOI: $10.21779 / 2500-1930-2017-32-4-73-79$

\title{
A.B. Иnатова
}

\section{О тенденциях развития институтов реализации промышленной политики в Ростовской области ${ }^{10}$}

Южный федеральный университет; Россия, 344002, г. Ростов-на-Дону, ул. М. Горько2o,88; ipatova_a_v@mail.ru

Статья посвящена анализу базовых институтов реализации экономической политики государства в условиях выхода из кризиса. Теоретико-методологической основой исследования выступает теория развития как структурный элемент экономической науки. Акцент сделан на необходимости использования «институтов развития» как основных структурных элементов промышленной политики, выступающей элементом экономической политики государства. Автором иллюстрируются направления формирования системно-инновационных преобразований субъектов промышленности, исходя из приоритета действенности их целей функционирования и соответствия общегосударственных приоритетов. Доказывается необходимость снижения асимметрии экономической информации между ее участниками. Эмпирической базой проведенного исследования выступили результаты проводимого социоэкономического обследования субъектов промышленной политики на региональном уровне.

Ключевые слова: экономическая политика, промышленная политика, институты развития.

Современное состояние экономической системы характеризуется неустойчивостью, наличием кризисных явлений, обусловленных влиянием общеэкономической нестабильности, санкциями. Замедление темпов снижения ВВП, оживление экономики свидетельствуют о выходе российской экономики из фазы кризиса. В связи с этим высветилась необходимость определения контуров новой парадигмы экономического развития, поскольку, как показал кризис, ресурсная зависимость не обеспечивает устойчивости и долгосрочности развития. Новая модель экономического развития, на наш взгляд, должна основываться на человеческом капитале и технологических инновациях. Как в период кризиса, так и в посткризисное время параметры национального хозяйства России определяются в первую очередь характером макроэкономической среды [1, c. 9; 2, с. 14]. В сложившихся сегодня экономических и социальных условиях с каждым днем повышается необходимость в эффективной работе и развитии бизнес-структур как ключевых игроков российской экономики, определяющих основу социальноэкономического развития страны в настоящем и будущем. Главная роль в процессе формирования среднего класса сегодня отводится именного этому способному стать надежной опорой российского общества сектору экономики.

В таких условиях долговременный экономический рост способен реализовываться только при эффективных институтах экономической политики в целом и отдельных

\footnotetext{
${ }^{10}$ Статья подготовлена при финансовой поддержке РФФИ (проект «Институты реализации новой промышленной политики» № 16-02-00469). Статья подготовлена по материалам доклада, представленного на III Международной научно-практической конференции «Модернизация экономических систем: опыт и перспективы», которая прошла 27-28 апреля 2017 года в Дагестанском государственном университете (г. Махачкала, РФ).
} 
Ипатова A.B. О тенденциях развития институтов реализации промышленной политики в Ростовской области

ее составляющих, в частности промышленной политики [3, с. $12 ; 4$, с. 10]. Следует отметить многогранность имеющихся исследований по вопросам осуществления промышленной политики в современной литературе. Так, В. Тамбовцев анализирует необходимость построения теоретической конструкции промышленной политики [5]; Осьмаковым В. и Калининым А. представлена проблематика промышленного развития с точки зрения возникающих вызовов государственной политики [6]. Однако для реализации целей статьи следует конкретизировать, что под промышленной политикой следует рассматривать системноподчиняющиеся инструменты, использование которых состоит в минимизации проявляющихся в условиях рыночной экономической системы так называемых «провалов рынка», а также позволяющих сформировать комплекс благоприятных условий для ведения хозяйственной деятельности, что в конечном итоге позволяет создать генетически сформированную направленность функционирования экономической структуры в условиях реализации политики экономического развития. Таким образом, промышленная политика в современной экономике выступает эффективным институтом, функционирующим за счет взаимодействия элементов координационных действий всех субъектов рыночной экономики, но прежде всего государства и предприятий.

Системообразующее влияние промышленной политики проявляется, с одной стороны, в механизме создания подсистемы конкурентных преимуществ базового экономического субъекта - государства; с другой стороны в формировании комплекса условий для экономической безопасности. На наш взгляд, формирование экономического роста в контексте создания условий для реализации эффективной промышленной политики на уровне региона должно осуществляться посредством функционирования «институтов развития» - системы организаций и структур, создаваемых государственными органами управления для нивелирования влияния «провалов рынка» на долгосрочной основе. В качестве конкретного примера рассматриваемого института выступает Фонд развития промышленности, который был сформирован путем преобразования Российского фонда технологического развития в 2014 году с целью финансирования проектов по импортозамещению в отраслях пищевой промышленности, сельскохозяйственного и нефтяного машиностроения и комплектующих. Кроме того, в рассматриваемый период времени был издан Федеральный закон № 488-Ф3 от 31 декабря 2014 г. «О промышленной политике Российской Федерации», предполагающий создание следующего комплекса институциональных элементов: «инвестиционный контракт, поддержка проектов, финансируемых Фондом развития промышленности, создание промышленных парков» [7].

В Ростовской области создание элементов кластеризации промышленной политики также регламентируется изданным в 2015 г. законодательным актом - Областным законом «О промышленной политике» от 20 октября 2015 г. № 418-3С [8]. Кроме того, Правительством области осуществляется комплекс мер, основанных на «Концепции кластерного развития〉 Ростовской области до 2020 года, которые предусматривают объем инвестиций в размере 25,5 млрд руб. и совокупный объем по отгруженным товарам, работам и услугам по итогам 2020 года в сумме 370 млрд руб. [9, с. 86]. Изложенное позволяет заключить, что создание соответствующей институциональной основы для работы институтов развития новой промышленной политики с учетом координации всех уровней управления - от мезо- до макроуровня регулирования хозяйственных процессов необходимо.

Уровень промышленного развития Ростовской области за последние годы демонстрирует высокие темпы (до 50 \% прироста в 2016 г.), поэтому важной задачей является

74 Вестник Дагестанского государственного университета.

Серия 3. Общественные науки. 2017. Том 32. Вып. 4 
Ипатова А.В. О тенденциях развития институтов реализации промышленной политики в Ростовской области

выявление конкретных институтов развития, способствующих такому росту в наибольшей степени. В настоящем исследовании под «институтом развития» нами подразумевается, с одной стороны, инструмент государства, способствующий социально-экономическому развитию и процессам модернизации экономики (институционально-правовая составляющая), с другой стороны, организационная структура, осуществляющая формирование и реализацию масштабных социально-экономических проектов (организационная составляющая: технопарки, особые экономические зоны, Инвестиционный фонд Российской Федерации и т. д.). Однако для их комплексного взаимодействия необходимо соответствие между базовыми целями, которые ставит государство при их формировании, и целями, которые преследуют конкретные участники промышленной политики (фирмы).

В настоящее время институт развития является своеобразным инструментом, который компенсирует, с одной стороны, «провалы» рыночных институтов, с другой неэффективность функционирования деятельности конкретных правительственных структур. Таким образом, институты развития следует рассматривать как инфраструктурную составляющую для реализации приоритетов структурной политики на долговременной основе, когда возможно достижение целей экономического развития за счет модернизационного механизма российской экономики.

Общая схема региональных институтов представлена на рисунке 1 , который демонстрирует обязательные финансовые и организационные структуры в системе регулирования и реализации мер промышленной политики. Именно институты развития выступают катализаторами частных инвестиций в пределах приоритетных (с точки зрения государства) сфер экономики. Они создают условия для формирования соответствующей инфраструктуры, обеспечивая доступ предприятий к конкретным источникам финансирования и информационным базам.

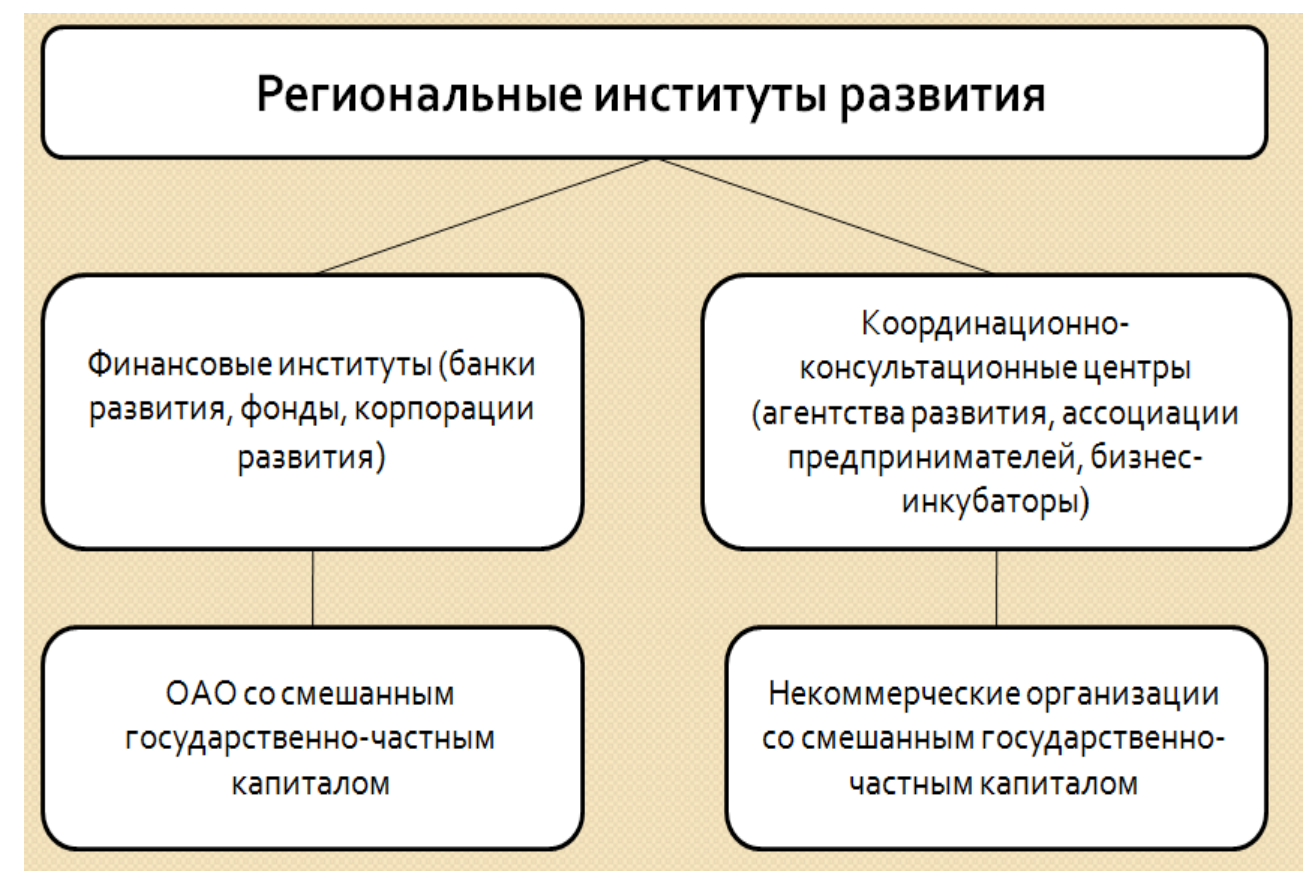

Рис. 1. Базовые институты развития в рамках реализации промышленной политики на уровне региона 
Ипатова A.B. О тенденциях развития институтов реализации промышленной политики в Ростовской области

Несмотря на некоторую стихийность формирования, институты развития заняли определенную нишу в национальной инновационной структуре и доказали свою состоятельность. Фактически сегодня можно выделить три уровня функционирования институтов развития в зависимости от того, кто является инициатором их создания: федеральные институты развития, федеральные институты развития на региональном уровне, региональные институты развития.

В целом формирование институтов развития в регионах происходило в большей степени под влиянием федеральных властей, когда в регионах необходимо было наличие структур, через которые государственные программы могли быть реализованы на местах. В результате этого на сегодняшний день в регионах сформировался следующий механизм взаимодействия федеральных и региональных инициатив: на федеральном уровне имеется некая структура, которая выполняет роль координатора и регулятора деятельности региональной сети.

Проводимое в рамках научно-исследовательского проекта экономико-социологическое обследование институтов реализации новой промышленной политики на современном этапе демонстрирует асимметричность имеющейся у субъектов промышленного сектора информации; отмечается дифференцированность в ранжировании приоритетных мер проводимой промышленной политики на уровнях государства, Ростовской области и муниципалитета. Данный вывод свидетельствует о необходимости выделения сектора быстрорастущих компаний промышленного сектора с целью выработки приоритетных направлений их государственной поддержки [10].

Другим значимым объектом исследования в рамках реализуемого гранта РГНФ № 16-02-00469 «Институты реализации новой промышленной политики» стало изучение воздействия ситуации кризисного состояния региональной экономики на параметры, результаты и достигаемые цели при модернизации промышленной политики в период 2015-2016 гг. В частности, объектом анализа выступила проблема преодоления возможных кризисных явлений на предприятиях-участниках исследования. В результате опросов была получена следующая информация: 40 \% респондентов ответили, что не уверены в росте выручки на своем предприятии в ближайший год; $33 \%$ не уверены в преодолении кризисных явлений в ближайший год; 15 \% предполагают возможность роста совокупного дохода на своем предприятии в ближайший год; 12 \% полностью уверены в преодолении кризисных явлений в ближайший год. Следовательно, имеет место крайне неблагоприятная оценка перспектив улучшения экономической ситуации относительно базовых показателей функционирования предприятий в ближайшей перспективе.

Рис. 2 демонстрирует наибольшее воздействие на экономическое положение предприятия фактора изменяющегося потребительного поведения (50 \% опрошенных); в то же время $25 \%$ опрошенных отмечают изменения в инструментах регулирования отрасли, в которой осуществляется функционирование предприятия; 14 \% выделяют изменения в каналах сбыта; и только $11 \%$ отмечают негативное действие увеличения числа конкурентов в отрасли. 
Ипатова А.В. О тенденциях развития институтов реализации промышленной политики в Ростовской области
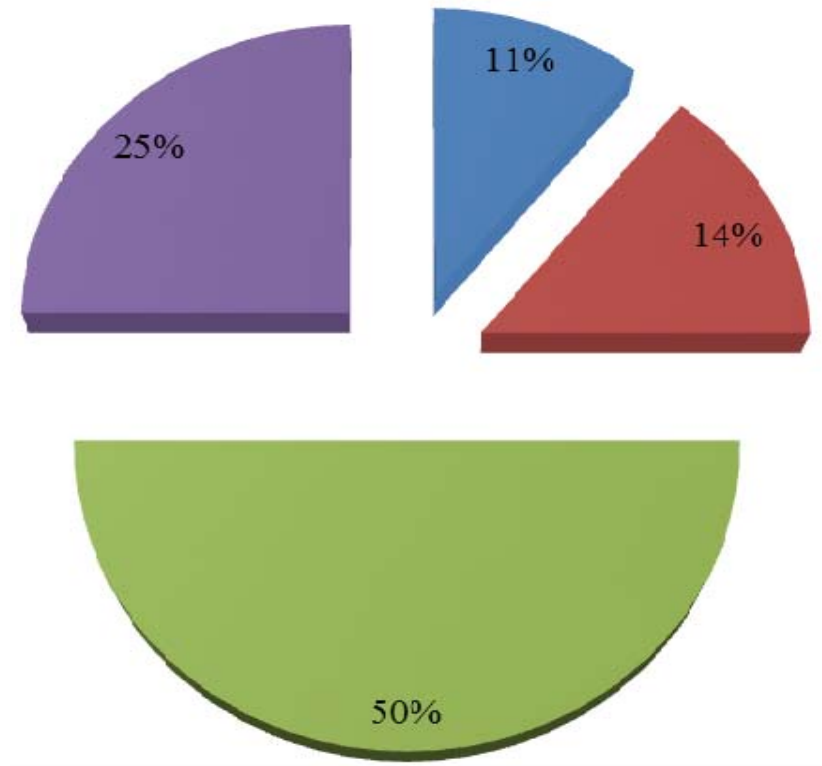

Швеличение числа конкурентов

ш изменения в каналах сбыта

изменение в поведении потребителей и производителей

ш изменения в регулировании отрасли

Рис. 2. Оценка влияния проявления кризиса на рыночное поведение предприятий-респондентов

Источник: составлено автором по материалам собственного социо-экономического обследования в рамках реализации проекта РГНФ № 16-02-00469 «Институты реализации новой промышленной политики»

В качестве значительных неблагоприятных условий для изменения конкурентных позиций на рынке фирмы-респонденты отмечают следующие факторы: 32 \% выделяют тенденцию колебания валютного курса; 30 \% отмечают неблагоприятную политическую ситуацию; 14 \% респондентов заявляют о необходимости изменения технологической составляющей производственного процесса.

Таким образом, институты развития в рамках реализации направленности промышленной политики в сторону создания механизма эффективных структурных элементов на уровне региона позволяют скоординировать взаимодействие всех участников данного процесса, снизить асимметрию рыночной информации, в т. ч. за счет:

- наличия стратегической поддержки наиболее перспективных отраслей экономики и отдельных экономических субъектов, демонстрирующих высокие производственные показатели (в частности, в Ростовской области - «Юг Руси», «Роствертол», «Агроком» и т. д.);

- минимизации последствий от проявляющихся «провалов рынка» и «провалов государства» за счет коррекции экстерналий (поддержка образования и науки, развитие транспортной системы, формирование инфраструктуры и т. д.);

- создания институциональных предпосылок для развития национальных отраслей за счет реализации стратегии ускоренного развития;

- использования института электронной торговли как базового элемента взаимодействия с зарубежными странами, предполагающего активное развитие, в частности, интернет-торговли;

- формирования совместных структур между образовательными организациями и предпринимательским сектором для трансляции инновационных знаний и технологий.

Выход экономического развития на содержательно новую составляющую экономического роста - инновационное развитие - должен включать смену направленности в 
Ипатова A.B. О тенденциях развития институтов реализации промышленной политики в Ростовской области

функционировании институтов развития промышленной политики, предполагающую, с одной стороны, необходимость учета специализации конкретных регионов [11], а с другой - учет интересов конкретных хозяйствующих субъектов, что позволит снизить уровень асимметричности рыночной информации и сформировать действенную модель промышленной политики региона.

\section{Литература}

1. May B. Уроки стабилизации и перспективы роста: экономическая политика России в 2016 году // Вопросы экономики. - 2017. - № 2.

2. Медведев Д. Социально-экономическое развитие России: обретение новой динамики // Вопросы экономики. - 2016. - № 10.

3. Идрисов Г.И. Промышленная политика России в современных условиях. - М.: Изд-во Ин-та Гайдара, 2016. - 160 с. (Научные труды / Ин-т экономической политики им. Е.Т. Гайдара; № 169Р).

4. Бухвальд E.M. Трудные пути становления промышленной политики в России // Экономика: вчера, сегодня, завтра. - 2015. - № 1-2.

5. Тамбовцев $B$. Нуждается ли промышленная политика в теоретических оправданиях // Вопросы экономики. - 2017. - № 5.

6. Осьмаков B., Калинин A. О стратегии развития промышленности России // Вопросы экономики. - 2017. - № 5.

7. Федеральный закон от 31 декабря 2014 г. № 488-Ф3 «О промышленной политике в Российской Федерации» // http://rg.ru/2015/01/12/promyshlennost-dok.html - Дата обращения 18.04.2017.

8. Областной закон от 20 октября 2015 г. № 418-3С «О промышленной политике» $\quad / / \mathrm{http}: / / w w w . d o n l a n d . r u / d o c u m e n t s / O-p r o m y s h l e n n o j j-p o l i t i k e-v-R o s t o v s k o j j-$ oblasti?pageid=128483\&mid=134977\&itemId=23050 - Дата обращения 18.04.2017.

9. Ипатова А.В. Об использовании методологии институционального проектирования в реализации мер новой государственной промышленной политики // Государственное и муниципальное управление. Ученые записки СКАГС. - 2016. - № 2.

10. Медовников Д., Оганесян Т., Розмирович С. Кандидаты в чемпионы: средние быстрорастущие компании и программы их поддержки // Вопросы экономики. - 2016. № 9.

11. Земиов $C$., Баринова B. Смена парадигмы региональной инновационной политики в России: от выравнивания к «умной специализации»// Вопросы экономики. 2016. - № 10 .

Поступила в редакиию 14 июня 2017 г. 
UDK 3.33.338.2

DOI: $10.21779 / 2500-1930-2017-32-4-73-79$

\section{On the trends of development of industrial policy implementation institutions in Rostov region ${ }^{11}$}

\section{A.V. Ipatova}

Southern Federal University; Russia, 344002, Rostov-on-Don, M. Gorky st., 88; ipatova_a_v@mail.ru

The article analyzes the basic institutions of the economic policy of the state in terms of overcoming the crisis. Theoretical and methodological basis of research is the theory of development as a structural element of economic science. Emphasis is placed on the need to use "institutions" as the main structural elements of industrial policies as an element of economic policy. The author illustrates the formation of a system-innovative transformations of constituent entities of the industry, based on the priority of effectiveness of their objectives and compliance with national priorities. The necessity of reducing the asymmetry of economic information among its members. The empirical basis of the conducted research was the findings of the ongoing socio-economic surveys of subjects of industrial policy at the regional level. This article was prepared with financial support of RFBR (the project "The institutes of the implementation of the new industrial policy" № 16-02-00469).

Keywords: economic policy, industrial policy, development institutions.

Received 14 June, 2017

${ }^{11}$ This article was prepared with financial support of RFBR (the project "The institutes of the implementation of the new industrial policy" № 16-02-00469) (Owner.: Ph. D., associate Professor of the Department of economic theory, Southern Federal University A.V. Ipatova). 